\title{
SCOLIOSIS SURGERY AND ITS EFFECT ON BACK SHAPE
}

\author{
R. J. JEFFERSON, I. WEISZ, A. R. TURNER-SMITH, J. D. HARRIS, G. R. HOUGHTON
}

From Oxford Orthopaedic Engineering Centre, Nuffield Department of Orthopaedic Surgery and Department of Orthopaedic Surgery, Oxford

\begin{abstract}
Thirty-four patients with adolescent idiopathic scoliosis were assessed by radiography and the integrated shape imaging system (ISIS) both before and after spinal surgery. Twenty-seven patients underwent Harrington instrumentation, after which lateral indices of curvature were significantly improved, but changes in the transverse plane were less pronounced. Sublaminar wiring was carried out in two patients whose thoracic lordosis was corrected by the surgery. Five patients whose severe deformity had persisted after previous spinal surgery underwent costoplasty, which resulted in a significant improvement in back shape measurements. We conclude that the cosmetic deformity of the back in scoliosis is only partially corrected by operations on the spine itself, whilst costoplasty addresses the problem directly, and improves the surface shape.
\end{abstract}

Scoliosis is an unpleasant deformity which is severe enough to warrant assessment and possible treatment in about $0.3 \%$ of the population (Keim 1979; DeSmet et al. 1981). The aetiology is unknown in about $70 \%$ of cases. In these idiopathic cases, any progression is most rapid during the adolescent growth spurt, and a small proportion of patients reach the point where surgical intervention is necessary. The aims of surgery are to increase the stability of the spine, to prevent further progression of the curvature, to improve pulmonary function, and to improve the appearance (Weinstein, Zavala and Ponseti 1981; Turner-Smith and Harris 1985). The conventional method of assessment, either of curve progression or of the changes resulting from surgery, is radiography. Anteroposterior and sagittal views enable the clinician to measure the coronal and sagittal components of the three-dimensional deformity, but give little indication of changes in the cosmetic deformity.

R. J. Jefferson, PhD, Research Bioengineer, Oxford Orthopaedic Engineering Centre

A. R. Turner-Smith, DPhil, Research Officer, Oxford Orthopaedic Engineering Centre

J. D. Harris, MA, Director, Oxford Orthopaedic Engineering Centre G. R. Houghton, MA, FRCS, Consultant Orthopaedic Surgeon Nuffield Orthopaedic Centre, Headington, Oxford OX3 7LD, England.

I. Weisz, MD, Consultant Orthopaedic Surgeon

Department of Orthopaedic Surgery A, Rambam Medical Centre, Haifa, Israel.

Requests for reprints should be sent to Dr R. J. Jefferson.

(C) British Crown copyright 1988

$0301-620 X / 88 / 2064 \$ 2.00$

J Bone Joint Surg [Br] 1988;70-B:261-6.
Stimulated by previous experience in the evaluation of back shape as a method of assessing the cosmetic deformity in scoliosis (Verrier et al. 1979), an automated stereophotogrammetric technique, ISIS - integrated shape imaging system (Turner-Smith and Harris 1986) has been developed. An ISIS scan provides the clinician with a safe and repeatable means of assessing the surface shape of the back in three dimensions and of monitoring objectively any changes that occur. These changes in back shape will reflect the effectiveness of any treatment regime. In this study we demonstrate the effectiveness of three different types of surgery for scoliosis in terms of the resulting changes in shape as measured by ISIS.

\section{MATERIALS AND METHODS}

The study group of patients was selected from the clinic population at the Nuffield Orthopaedic Centre. It comprised 34 patients ( 4 male, 30 female) all diagnosed as having adolescent idiopathic scoliosis, and with the major curve component in the thoracic region. They had all undergone corrective surgery during the two-year period covered by the study, their age range at the time of operation being 12 to 20 years (mean 15.25 years). All clinical decisions were made and all surgery performed by one person only. The patients were classified according to their operative treatment. Twenty-seven patients underwent Harrington instrumentation, two patients (with marked lordosis) were treated by Harrington-Luque instrumentation and five patients underwent costoplasty. The patients in this third group had all undergone previous surgical correction of a scoliotic curve, whether fusion in situ (three patients) or Harrington instrumentation (two patients), but deformity per- 
sisted as a cosmetically disfiguring rib hump, which the surgery aimed to reduce.

All the patients were assessed both radiographically and with ISIS scans both before and after surgery. The pre-operative assessments were carried out on the day before operation and the postoperative 12 months afterwards. The radiographs were evaluated by the Cobb method (Cobb 1948), so that any changes in lateral curvature were shown as variations in the Cobb angle. From the ISIS scans produced in the standard manner in the scoliosis clinic (Turner-Smith et al. 1988), the parameters chosen for patient assessment were spine length, lateral asymmetry, volumetric asymmetry, hump severity, maximum surface angle and maximum area difference.

Table I. Changes in radiographic and ISIS parameters after Harrington instrumentation in 27 patients

\begin{tabular}{llll}
\hline Parameter & Improved & Unchanged & Worse \\
\hline Spine length* & 23 & 4 & - \\
Cobb angle & 27 & - & - \\
Lateral asymmetry & 27 & - & - \\
Maximum surface angle & 18 & 6 & 3 \\
Maximum area difference & 19 & 2 & 6 \\
Volumetric asymmetry & 13 & 7 & 7 \\
Hump severity & 18 & 3 & 6
\end{tabular}

"For spine length, "improved" = increased

Table II. Comparison of radiographic and ISIS parameters before and after Harrington instrumentation

\begin{tabular}{|c|c|c|c|}
\hline \multirow[b]{2}{*}{ Parameter } & \multicolumn{2}{|c|}{ Mean value \pm s.d. } & \multirow{2}{*}{$\begin{array}{l}\text { Significance } \\
\text { of } \\
\text { difference }\end{array}$} \\
\hline & Before & After & \\
\hline Spine length & $410 \pm 37 \mathrm{~mm}$ & $442 \pm 29 \mathrm{~mm}$ & $\mathrm{p}<0.0001$ \\
\hline Cobb angle & $58 \pm 9^{\circ}$ & $32 \pm 8^{\circ}$ & $p<0.0001$ \\
\hline Lateral asymmetry & $52 \pm 9^{\circ}$ & $28 \pm 9^{\circ}$ & $p<0.0001$ \\
\hline $\begin{array}{l}\text { Maximum surface angle } \\
\text { Surface angle } \\
\text { at same level }\end{array}$ & $15 \pm 5^{\circ}$ & $\begin{array}{r}10 \pm 6^{\circ} \\
9 \pm 6^{\circ}\end{array}$ & $\begin{array}{l}\mathrm{p}<0.001 \\
\mathrm{p}<0.001\end{array}$ \\
\hline $\begin{array}{l}\text { Maximum area difference } \\
\text { Area difference } \\
\text { at same level }\end{array}$ & $36 \pm 15$ & $\begin{array}{l}29 \pm 18 \\
27 \pm 17\end{array}$ & $\begin{array}{l}p<0.01 \\
p<0.001\end{array}$ \\
\hline Volumetric asymmetry & $24 \pm 13$ & $20 \pm 15$ & Non-significant \\
\hline Hump severity & $4.7 \pm 1.8$ & $3.6 \pm 2.2$ & $p<0.01$ \\
\hline
\end{tabular}

A detailed description of the technique, and the different parameters is given by Turner-Smith et al. (1988). Lateral asymmetry represents the lateral element of cosmetic deformity and may be considered as the surface analogue of the Cobb angle. The other parameters are used to quantify transverse asymmetry and provide an estimate of the cosmetic effects of the rotation of the vertebrae in a scoliotic spine. The surface angle
Table III. Assessment before and after Harrington-Luque instrumentation

\begin{tabular}{lcc}
\hline & Before & After \\
\hline $\begin{array}{l}\text { Ist patient } \\
\text { Spine length }\end{array}$ & $406 \mathrm{~mm}$ & $460 \mathrm{~mm}$ \\
Cobb angle & $65^{\circ}$ & $25^{\circ}$ \\
Lateral asymmetry & $76^{\circ}$ & $17^{\circ}$ \\
$\begin{array}{l}\text { Maximum surface angle } \\
\text { Surface angle at same level }\end{array}$ & $32^{\circ}$ & $9^{\circ}$ \\
$\begin{array}{l}\text { Maximum area differences } \\
\text { Area at same level }\end{array}$ & 56 & $8^{\circ}$ \\
Volumetric asymmetry & & 41 \\
Hump severity & 22 & 31 \\
$\begin{array}{l}\text { 2nd patient } \\
\text { Spine length }\end{array}$ & 6.3 & 24 \\
Cobb angle & $368 \mathrm{~mm}$ & 4.8 \\
Lateral asymmetry & $73^{\circ}$ & $389 \mathrm{~mm}$ \\
Maximum surface angle & $71^{\circ}$ & $30^{\circ}$ \\
$\quad$ Surface angle at same level & $31^{\circ}$ & $37^{\circ}$ \\
Maximum area difference & & $21^{\circ}$ \\
$\quad$ Area at same level & 88 & $18^{\circ}$ \\
Volumetric asymmetry & 62 & 64 \\
Hump severity & 11.7 & 61 \\
\hline
\end{tabular}

represents the slope of the back surface at a particular level of the back; ISIS analysis divides the back into 10 evenly spaced levels between the vertebra prominens and the posterior iliac spines. The area difference represents the deviation from symmetry at an ISIS level in terms of the difference in area between the prominence on one side of the back and the relatively flat contralateral side. The volumetric asymmetry is the sum of the area differences and provides a single quantitative result for total back asymmetry. The hump severity is defined as the ratio of the volumetric asymmetry to the length (in terms of ISIS levels) over which the volume is calculated. This parameter thus distinguishes between a short sharp curve and a long gradual one.

The maximum surface angle and maximum area difference were compared in two different ways pre- and post-operatively:

(i) direct comparison of maximum values irrespective of any change in level postoperatively;

(ii) comparison of the maximum value pre-operatively with the corresponding postoperative value at the same level.

For the 27 patients undergoing Harrington instrumentation the pre- and post-operative values were statistically analysed using a paired $t$-test to assess the significance of the difference in the mean values produced by surgery. The numbers in both the Harrington-Luque and the costoplasty groups were too small for 


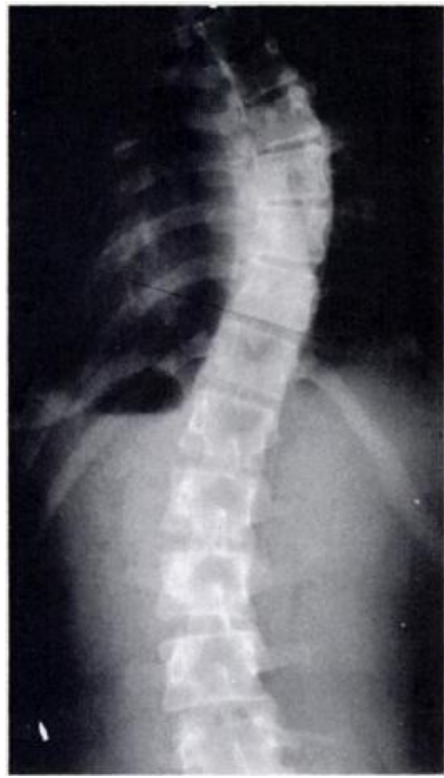

Fig. la

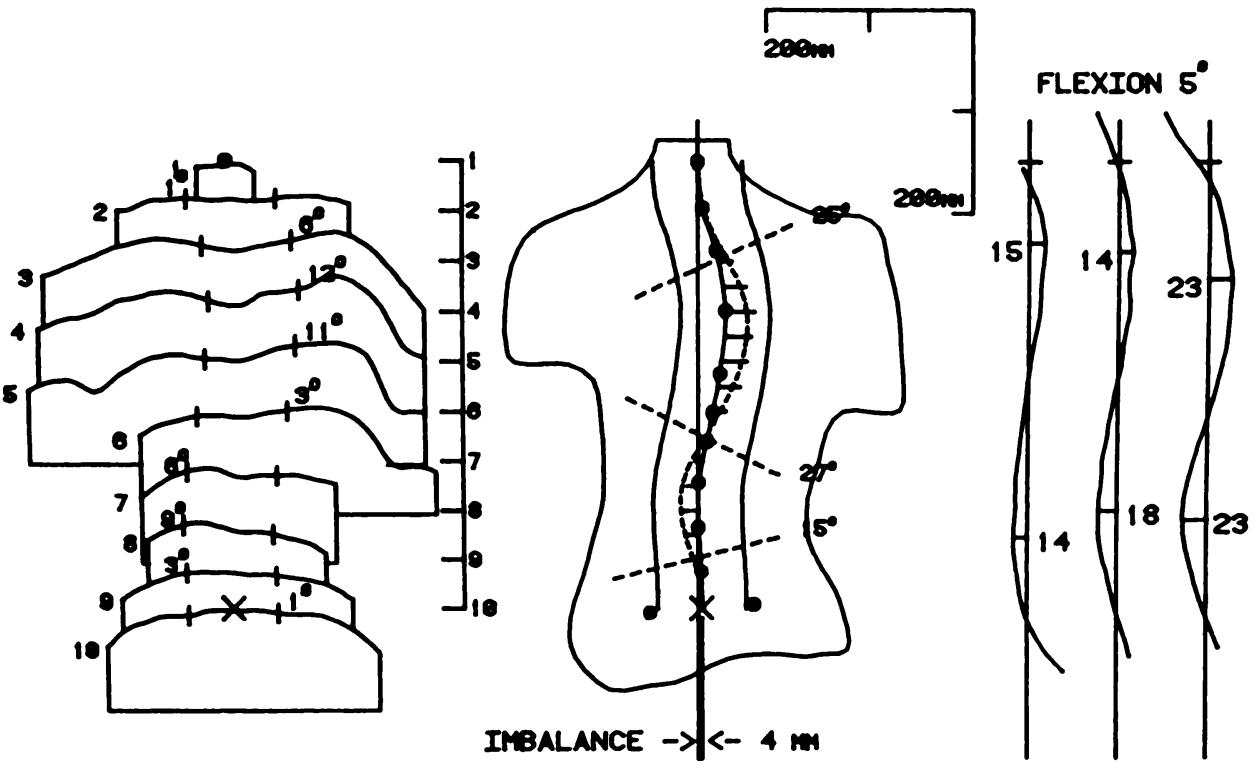

Fig. Ib

Pre-operative radiograph and ISIS scan for patient undergoing Harrington instrumentation. (Volumetric asymmetry, 16R, 4L; lateral asymmetry $52^{\circ} \mathrm{R}, 42^{\circ} \mathrm{L}$.)

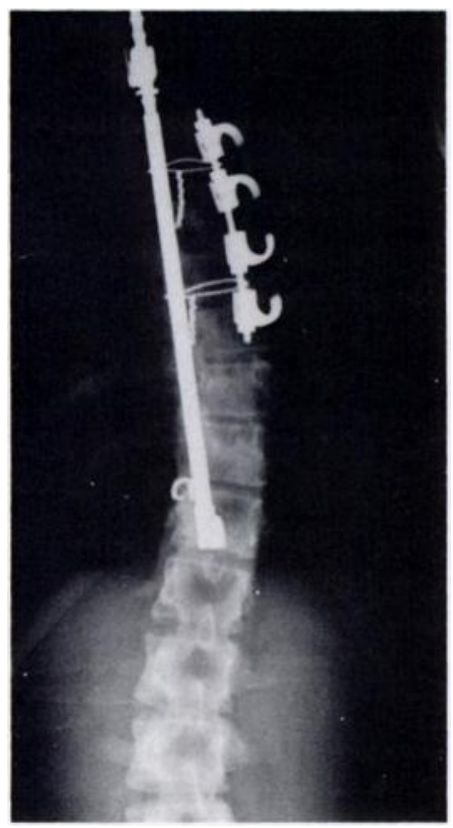

Fig. 2a

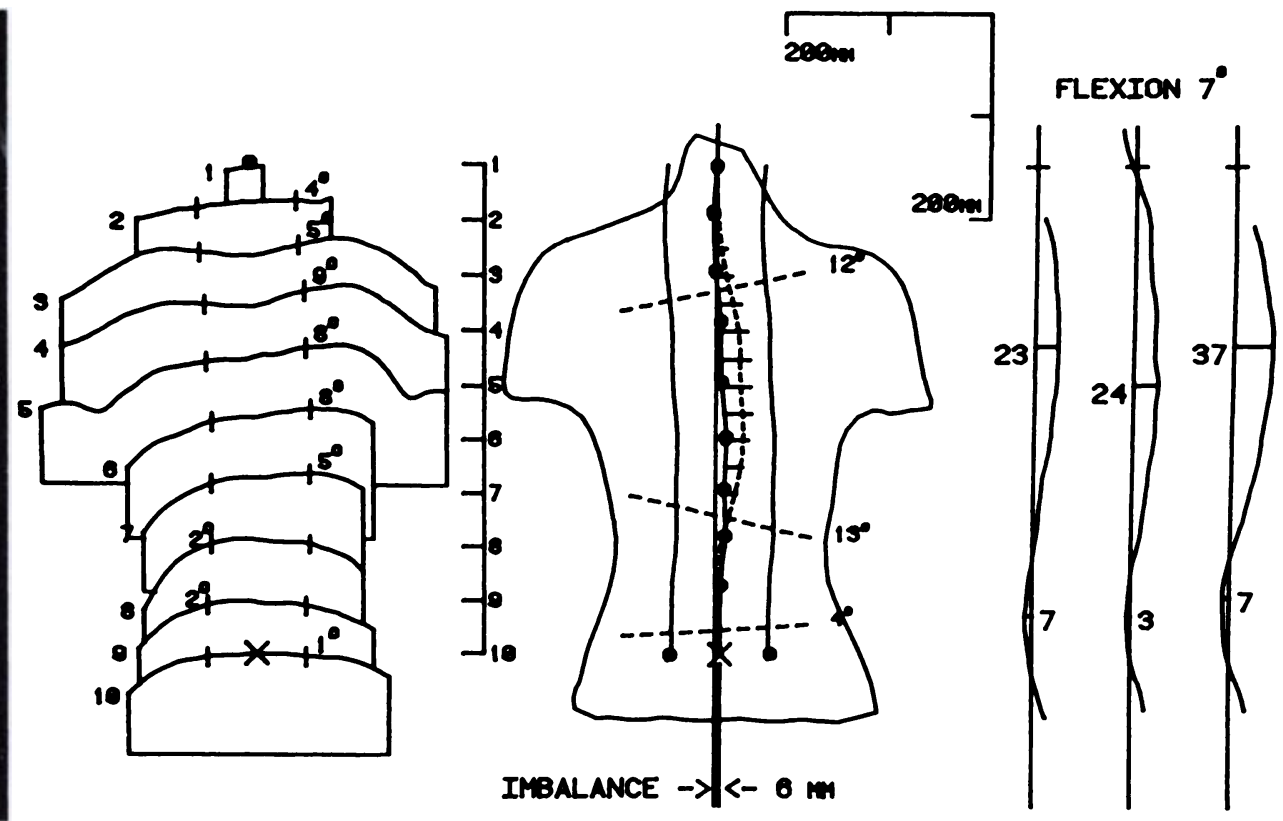

Fig. 2b

Postoperative radiograph and ISIS scan for patient shown in Figure 1. Note that the transverse asymmetry is virtually unchanged. (Volumetric asymmetry $22 \mathrm{R}$; lateral asymmetry $25^{\circ} \mathrm{R}, 17^{\circ} \mathrm{L}$.)

a similar statistical analysis to be meaningful so that the results were evaluated individually and therefore merely indicate trends.

\section{RESULTS}

Harrington instrumentation. Figures 1 and 2 show typical radiographs and ISIS scans for one patient before and after Harrington instrumentation. The correction of the thoracic curvature postoperatively is evident in both assessments. The effects of surgery on the transverse asymmetry can be identified from the difference between the two ISIS scans. Tables I and II show the changes in assessment parameters after Harrington instrumentation and their significance.

Harrington-Luque instrumentation. Illustrative results for the two patients undergoing Harrington-Luque instrumentation are shown in Figures 3 and 4. Figure $4 c$ shows more clearly the correction of the skin surface angle which is linked to the correction of the thoracic lordosis. The changes in assessment parameters are listed 


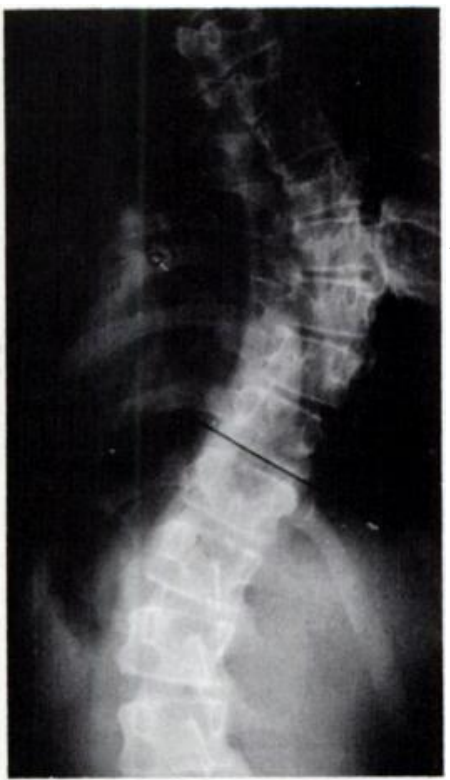

Fig. 3a

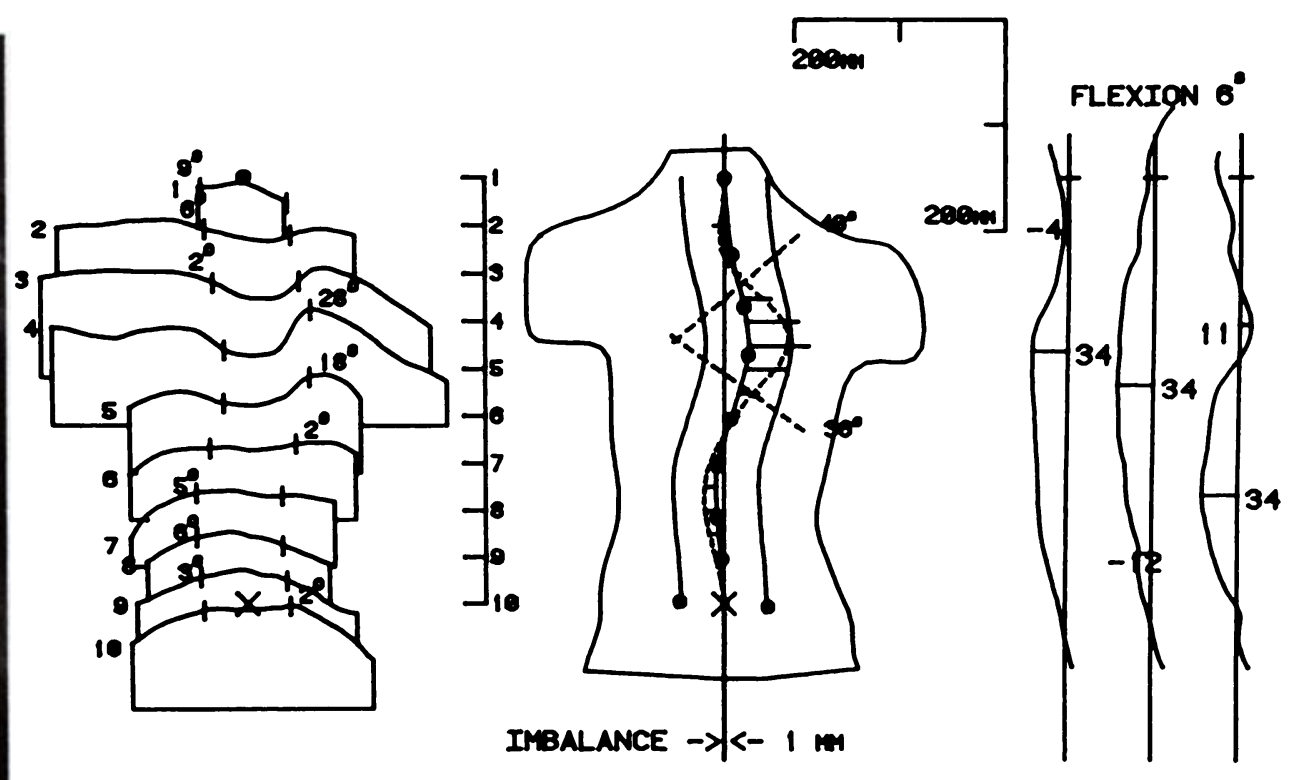

Fig. 3b

Pre-operative radiograph and ISIS scan for a patient undergoing Harrington-Luque instrumentation. (Volumetric asymmetry $22 \mathrm{R}, 4 \mathrm{~L}$ : lateral asymmetry $76^{\circ} \mathrm{R}$.)

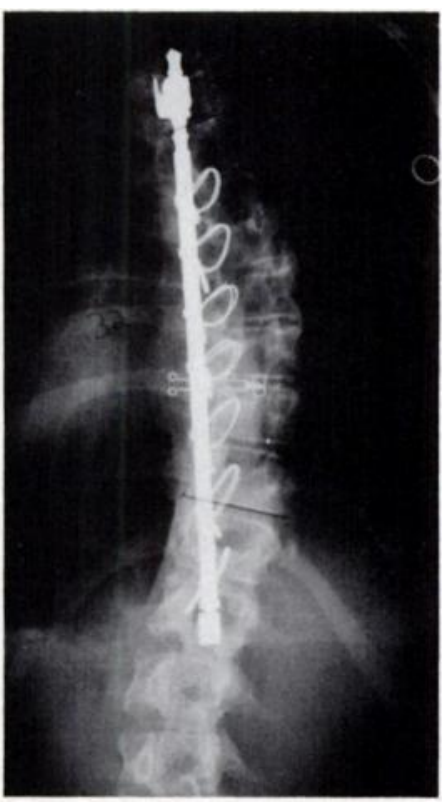

Fig. 4a

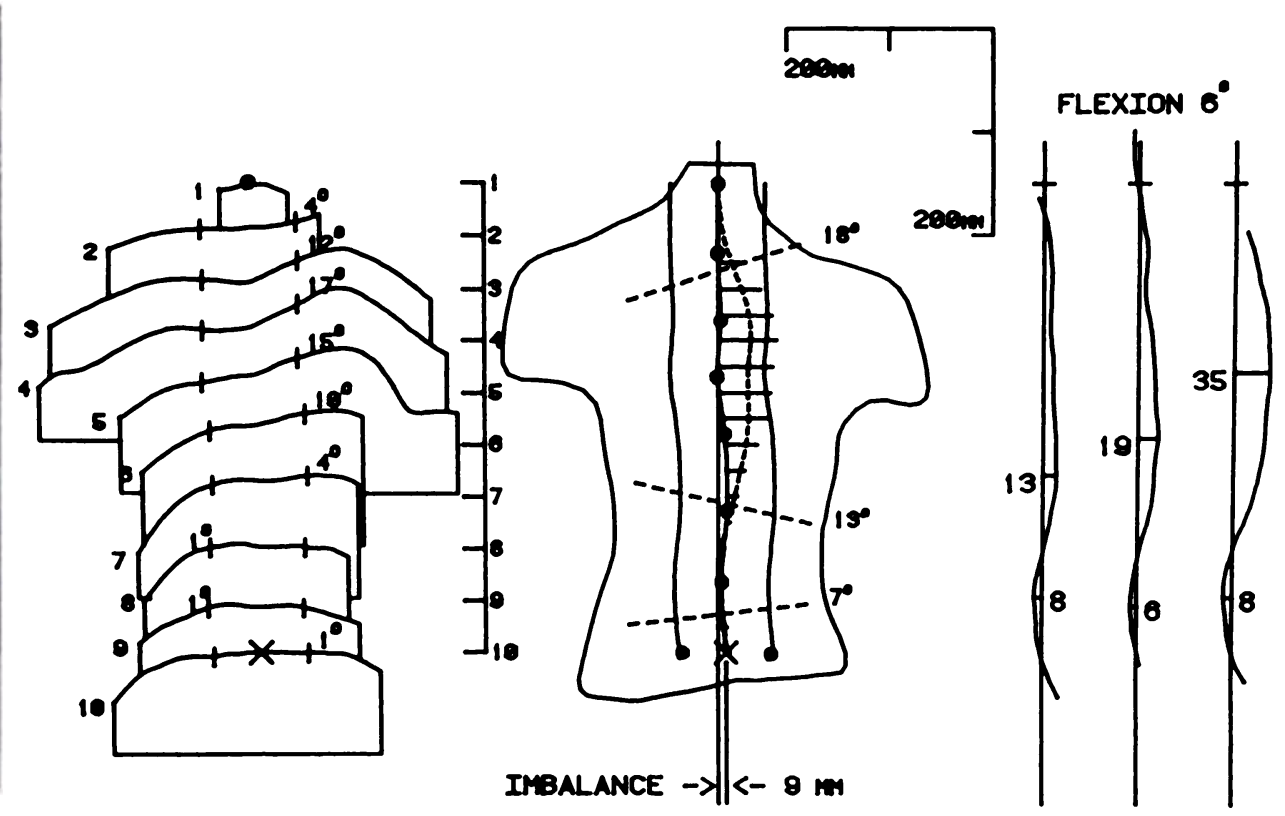

Fig. 4b

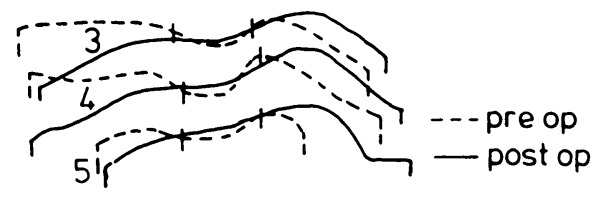

Fig. 4c

Postoperative radiograph and ISIS scan for the patient shown in Figure 3. (Volumetric asymmetry $40 \mathrm{R}$; lateral asymmetry $31^{\circ} \mathrm{R}, 20^{\circ} \mathrm{L}$.) Note the correction of the thoracic lordosis (Fig. 4c). 
Table IV. Changes in ISIS parameters after costoplasty

\begin{tabular}{|c|c|c|c|c|c|c|c|c|c|c|}
\hline & \multicolumn{2}{|c|}{ Lateral asymmetry } & \multicolumn{2}{|c|}{ Maximum surface angle } & \multicolumn{2}{|c|}{ Maximum area difference } & \multicolumn{2}{|c|}{ Volumetric asymmetry } & \multicolumn{2}{|c|}{ Hump severity } \\
\hline & Before & After & Before & After & Before & After & Before & After & Before & After \\
\hline Patient 1 & $53^{\circ}$ & $38^{\circ}$ & $12^{\circ}$ & $4^{\circ}$ & 31 & 15 & 18 & 6 & 4.8 & 2.0 \\
\hline Patient 2 & $45^{\circ}$ & $17^{\circ}$ & $15^{\circ}$ & $6^{\circ}$ & - & - & 30 & 4 & & \\
\hline Patient 3 & $68^{\circ}$ & $58^{\circ}$ & $29^{\circ}$ & $22^{\circ}$ & 84 & 68 & 72 & 86 & 9.6 & 9.0 \\
\hline Patient 4 & $55^{\circ}$ & $33^{\circ}$ & $24^{\circ}$ & $10^{\circ}$ & 57 & 32 & 48 & 28 & 8.2 & 4.0 \\
\hline Patient 5 & $61^{\circ}$ & $52^{\circ}$ & $23^{\circ}$ & $22^{\circ}$ & 80 & 72 & 74 & 60 & 10.7 & 8.3 \\
\hline
\end{tabular}

Fig. 5a

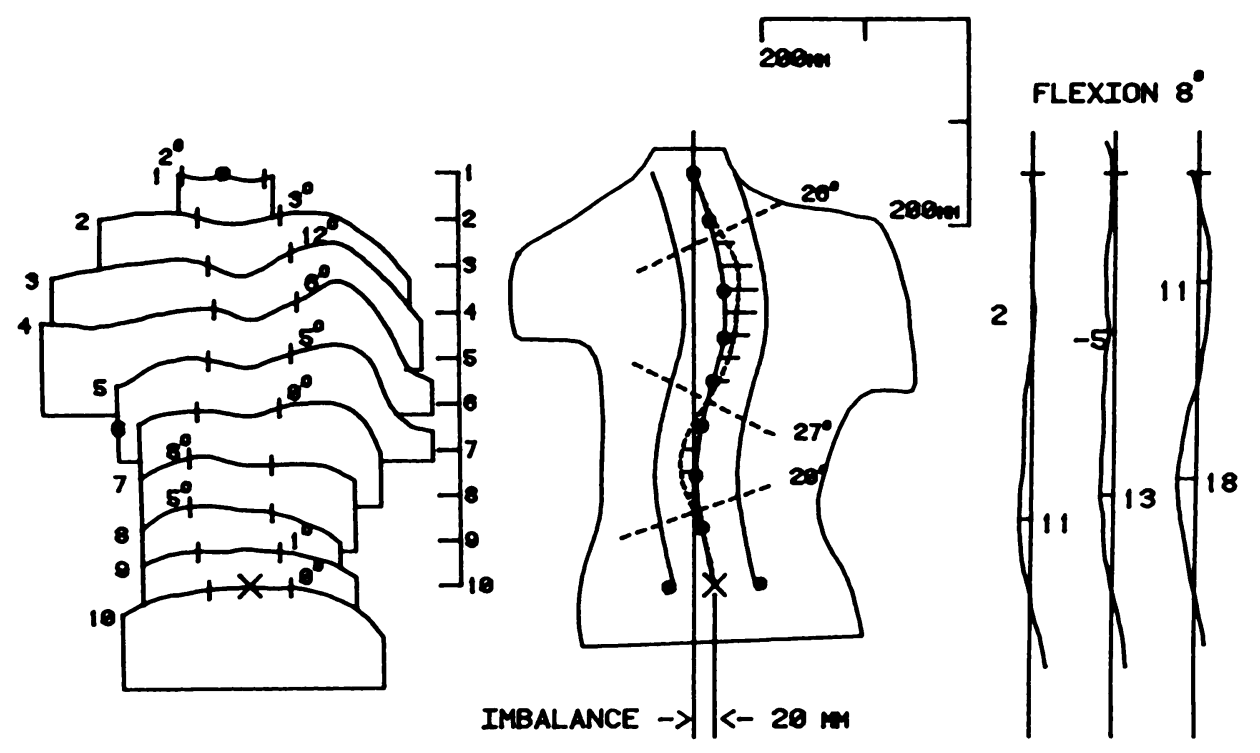

Fig. 5b

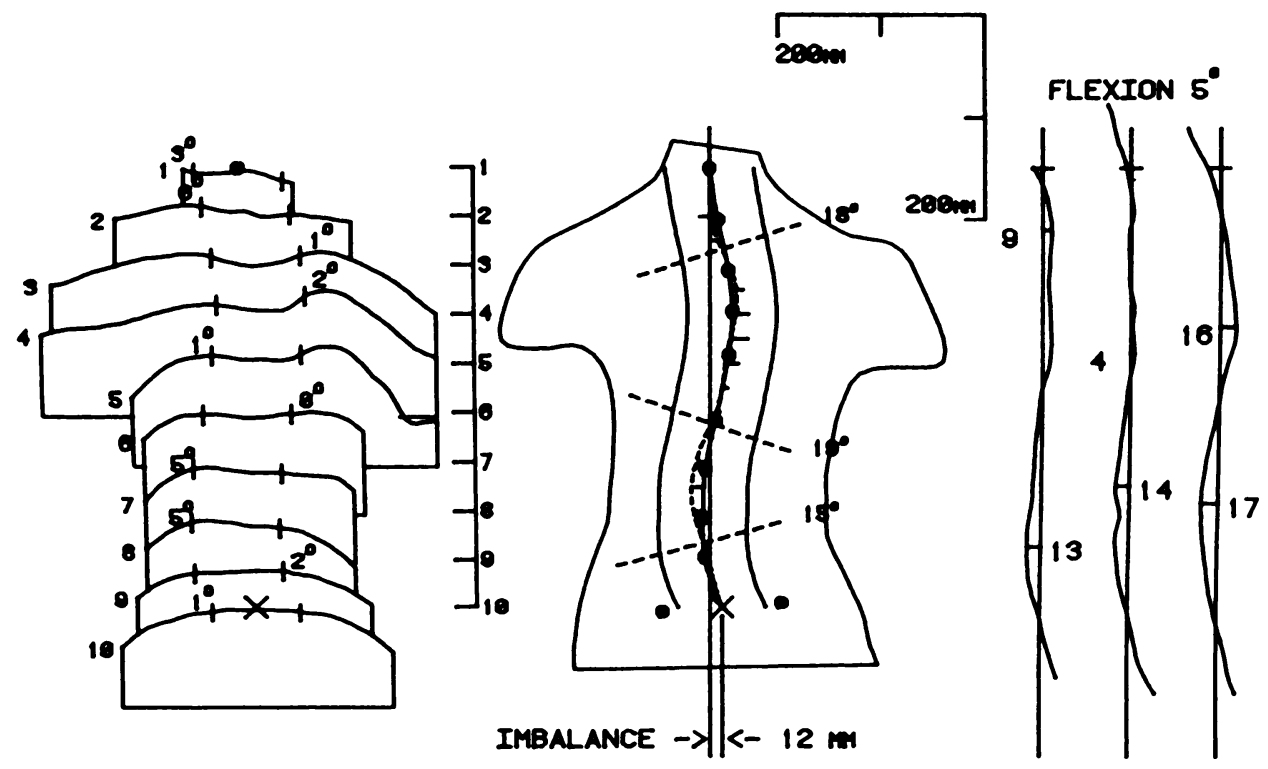

Fig. 5c

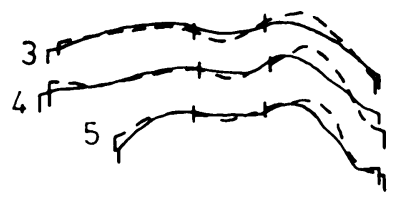

Pre- and post-operative ISIS scans for a patient undergoing costoplasty. (Volumetric asymmetry changes from $18 R, 4 L$ to

$6 \mathrm{R}, 2 \mathrm{~L}$; lateral asymmetry changes from $53^{\circ} \mathrm{R}, 47^{\circ} \mathrm{L}$ to $38^{\circ} R, 35^{\circ} \mathrm{L}$.) Note the change in - - pre op transverse asymmetry (Fig. $5 \mathrm{c}$ ). 
in Table III but without any statistical inferences because of the size of the group.

Costoplasty. The costoplasty group was also too small for statistical analysis, but typical ISIS scans are shown in Figure 5 and the results for the five patients are tabulated in Table IV. Figure $5 \mathrm{c}$ shows the three surface profiles after operation superimposed on the pre-operative profiles to emphasise the flattening of the rib prominence.

\section{DISCUSSION}

For the 27 patients in the Harrington group, Table II shows a highly significant difference $(p<0.0001)$ between pre- and post-operative values of the Cobb angle, a difference which was also observed in lateral asymmetry: the correction of the lateral curvature was in the region of $50 \%$. In conjunction with this effect there was a significant increase in the spine length (mean value $8 \%$ ), resulting from the straightening of the scoliotic curve. Assessment of transverse asymmetry showed that the maximum surface angle irrespective of level was significantly improved postoperatively, as was the maximum area difference, though this change was less significant. A comparison of both surface angle and area difference measurements at the same levels also showed a significant change postoperatively $(p<0.001)$.

In more than $50 \%$ of the patients the volumetric asymmetry was unchanged or worse postoperatively (Table I); this was the one parameter which showed no significant difference. However, the improvement in the hump severity was found to be significant at the $p<0.01$ level. These results may be explained from a consideration of the following factors:

(1) the length of the spine, and the length over which the volumetric asymmetry extends is significantly increased; (2) the maximum area difference is reduced significantly. The volumetric asymmetry remains unchanged because, although the elements of which it is comprised in the region of the prominence are significantly reduced, it is calculated over a greater length than previously. This would imply that care must be taken in the interpretation of the volumetric asymmetry with Harrington instrumentation, and in such cases the hump severity may be more meaningful.

In the Harrington-Luque group, there was a correction of more than $50 \%$ in both the Cobb angle and the lateral asymmetry (Table III). There were also good corrections of surface angle measurements with the area differences reflecting these changes, although less strongly. As with the Harrington group, there were only minimal improvements in the volume of the rib prominence, but the hump severity indicated an elongation of the curve. There has been good correction of the thoracic lordosis (Fig. 4c), which Dickson et al. (1984) point out is inherently unstable. Postoperatively a stable thoracic kyphosis has been created.

For the five patients in the costoplasty group the spine length and Cobb angle did not change significantly. This was to be expected since the spine was not operated upon in this procedure. However, there was a variable improvement in the lateral asymmetry. The best corrections in volumetric asymmetry and hump severity were obtained for this group of patients in whom surgery was specifically designed to reduce the rib prominence: Patient 1 showed an almost complete correction. The smallest improvement was seen in Patient 3 who had a particularly severe razor back deformity pre-operatively. The present results would suggest that costoplasty, by its direct approach to the rib cage, alters the shape of the back far more effectively than scoliosis surgery. However, the correction is variable, as it is dependent upon anatomical factors, and better corrections were obtained in the patients with less severe deformities (Patients 1, 2 and 4).

Conclusion. It appears that Harrington instrumentation is effective in correcting coronal plane deformity but is less effective in correcting asymmetry in the transverse plane. This is because it approaches the transverse problem indirectly, with elongation and flattening of the rib prominence being secondary to spinal distraction. Costoplasty addresses the transverse asymmetry problem directly, with more effective correction in all but the severest deformities.

\section{REFERENCES}

Cobb JR. Outline for the study of scoliosis. Am Acad Orthop Surg Instr Course Lect 1948;5:261-75.

DeSmet AA, Cook LT, Tariton MA, Asher MA. Assessment of scoliosis using three-dimensional radiographic measurements. Automedica $1981 ; 4: 25-36$.

Dickson RA, Lawton JO, Archer IA, Butt WP. The pathogenesis of idiopathic scoliosis: biplanar spinal asymmetry. J Bone Joint Surg [Br] $1984 ; 66-B: 8-15$.

Keim HA. Scoliosis. Clin Symp 1979;30:2-30.

Turner-Smith AR, Harris D. Shape measurement in the scoliosis clinic. In: Whittle MW, Harris D, eds. Biomechanical measurement in orthopaedic practice. Oxford: Clarendon Press, 1985:92-101.

Turner-Smith AR, Harris D. ISIS - an automated shape measurement and analysis system. In: Harris JD, Turner-Smith AR, eds. Surface topography and spinal deformity. Proceedings of the 3rd International Symposium, Oxford 1984. Stuttgart etc: Gustav Fischer, 1986:31-8.

Turner-Smith AR, Harris JD, Houghton GR, Jefierson RJ. A method for analysis of back shape in scoliosis. $J$ Biomech 1988: in press.

Verrier MC, Shillington ER, Wright TA, Crawford JS, Williams JI. Comparing methods of screening for scoliosis: testing for reliability and validity: a research report. Toronto: Health Care Research Unit, 1979

Weinstein SL, Zavala DC, Ponseti IV. Idiopathic scoliosis: long-term follow-up and prognosis in untreated patients. $J$ Bone Joint Surg [Am] $1981 ; 63-\mathrm{A}: 702-12$ 